of radiation source became an important consideration.

The social aspects of tuberculosis were discussed in this Section as well as in that of Public Health.

A large exhibition was organised representing practically every aspect of medical work. This was supplemented by additional exhibits of interest to special Sections, such as radiology, pathology, parasitology, anatomy, etc., but considerations of space do not allow of more detailed notice here.

The meeting was very largely attended. The work of the local committees resulted in a very wide choice of excursion to the visitors, which was highly appreciated by them.

\section{Einstein and the Philosophies of Kant and Mach.}

THE Bulletin de la Société Française de Philosophie for July I922, which has just been published (Armand Colin, Paris), contains the report of the reception of Prof. Einstein in Paris on April 6, I922. It is of exceptional interest, for Einstein did not make an original communication, but assisted at a discussion of the theory of relativity.

Prof. Langevin introduced the discussion, and Messrs. Hadamard, Cartan, Painlevé, Perrin, Becquerel, Brunschvicg, Le Roy, Bergson, Meyerson, and Piéron took part. It elicited from Einstein two pronouncements of special significance in regard to the relation of his theory first to Kant and secondly to Mach. We quote them in full. The first was in reply to $M$. Brunschvicg, who had said that the Kantian philosophy in separating a container, space and time, from a content, matter and force, had ended in antinomies, while Einstein's conception, which is characterised by the fact that container and content are inseparable, had delivered us from them. To this Einstein replied: "I do not think my theory accords with the thought of Kant, that is, with what that thought appears to me to be. What appears to me the most important thing in Kant's philosophy is that it speaks of a priori concepts for the construction of science. Now there are two opposite points of view: Kant's apriorism, according to which certain concepts pre-exist in our consciousness, and Poincarés conventionalism. Both agree on this point; that to construct science we need arbitrary concepts; but as to whether these concepts are given a priori or are arbitrary conventions, I am unable to say."

The second pronouncement was in reply to M. Meyerson, who had challenged him to declare how far he was in agreement with the theory of Mach. Einstein replied: "There does not appear to be a great relation from the logical point of view between the theory of relativity and Mach's theory. For Mach, there are two points to distinguish: on one hand there are the immediate data of experience, things we cannot touch ; on the other there are concepts which we can modify. Mach's system studies the existing relations between data of experience; for Mach, science is the totality of these relations. That point of view is wrong, and, in fact, what Mach has done is to make a catalogue, not a system. To the extent that Mach was a good mechanician he was a deplorable philosopher. His view of science, that it deals with immediate data, led him to reject the existence of atoms. Probably were he still with us he would change his opinion. I would like to say, however, that on the other point, namely, that concepts can change, I am in complete agreement with Mach."

$$
\text { No. } 2807 \text {, voL. I I 2] }
$$

\section{The Life-Cycle of the Protozoa.}

PROF. C. A. KOFOID delivered, on December 27 last in Boston, an address as vice-president of Section $F$ (Zoology) of the American Association for the Advancement of Science and as president of the American Society of Zoologists, on the life-cycle of the Protozoa (Science, vol. lvii. pp. 397-4o8, April 6, I923). He remarked that the striking similarities of the most ancient fossil Protozoa to recent afford some ground for the inference that the Protozoa living to-day differ but little from those when life was young. A consideration of the accounts of the origin de novo of nuclei from chromidia leads to the conclusion that adequate evidence of such origin is lacking. Prof. Kofoid holds that, as sound cytological investigation of the Protozoa progresses, it becomes increasingly evident that the descent of the nuclei and the individuality of the chromosomes, found in the Metazoa holds also for the Protozoa, and it may be inferred that the Protozoa are equipped with the essential structural basis-chromosomes and mitosis-for the mechanism of heredity.

The searcher for the origins of biological phenomena finds in the Protozoa a fertile but perplexing field. Here have arisen all the fundamental types of symmetry - spiral, leiotropic, dexiotropic, radial, bilateral, and modifications of these. Here also are several distinct types of mitosis, different locations of the centrosome, and extraordinary derivatives of this organ ranging from the nematocysts of Dinoflagellates to the complicated neuromotor system of the trichonymphid flagellates. Sex and sexual dimorphism have also had their origin in the Protozoa. Prof. Kofoid also refers to the universal occurrence of asexual reproduction in the Protozoa, and to the development after fertilisation of a multicellular stage, which he terms a somatella, in which there is generally no progress to the point of division of labour and differentiation of tissues, although the differentiation of sexual and somatic cells occurs in some cases, e.g. Volvox. The sequence of events within the cyst of Entamœba-involving elaboration of glycogen and the formation of the chromatoidal substance with its relation to the growth processes-is regarded as suggestive of the sequence in the egg and of the relationship of specific yolk substances to cleavage and differentiation in the metazoan egg. The observations of Jameson on maturation in the Sporozoa show that the haploid condition persists throughout the period of growth and asexual reproductions, while the diploid lasts but one cell-generation. Such conditions give occasion to wonder whether or not sexual reproduction may not have been elaborated gradually and independently within widely different groups in the Protista, and afterwards in them and in higher forms of life the diploid state has extended its domain more and more throughout the life-cycle.

Prof. Kofoid considers that the life-cycle of the malaria parasite - the zygote, the multicellular stage which follows and leads to the formation of sporozoites, which on introduction to man undergo growth and asexual reproduction to form merozoites, and the eventual production of gametocytes-may be compared with the fundamental processes of fertilisation, cleavage, asexual reproduction, and gametogenesis in the Metazoa, except that histogenesis and organ differentiation do not appear. $\mathrm{He}$ believes it may perhaps be helpful and serve to facilitate progress if we emphasise the similarities of organisms and seek to find the common processes underlying them all, rather than to emphasise their differences and thus obscure our vision of fundamental problems of life. 